\title{
Origem, ontologia, mito e política em Heidegger e Cassirer
}

\author{
Origin, ontology, myth and politics in Heidegger and Cassirer
}

\author{
ALEXANDRE DE OLIVEIRA FERREIRA \\ (Universidade Federal de São Paulo)
}

\begin{abstract}
Resumo: O presente artigo busca comparar as ontologias desenvolvidas por Heidegger e Cassirer mostrando que ambos possuem concepções distintas sobre a origem dos múltiplos sentidos do ser, as quais servirão para sustentar interpretações opostas acerca da ascensão do nacional-socialismo na Alemanha. Em Heidegger o sentido é pensado a partir de uma origem única: seja a temporalidade do Dasein (nas obras do entorno de Ser e Tempo), seja a epocalidade do ser no Heidegger tardio. Cassirer, por sua vez, pensa o ser como dado mediante uma multiplicidade de origens expressas nas formas simbólicas da cultura (mito, arte, ciência, linguagem, etc.). Curiosamente, ambos os filósofos se utilizarão de suas respectivas ontologias para pensar o surgimento do nacional-socialismo a partir da relação entre mito e técnica. Assim, no início dos anos de 1930, Heidegger pensa a história do ser (Geschichte des Seins) a partir da perspectiva de uma origem mito-poética, vendo o nacional-socialismo como uma possibilidade de retorno ao início grego do pensamento ocidental e da irrupção de um novo modo de doação do ser que pudesse superar o domínio planetário da técnica moderna. Cassirer, ao contrário, verá no nazismo uma infiltração indevida do elemento mítico na sociedade tecno-científica.
\end{abstract}

Palavras Chave: Heidegger, Cassirer, ontologia, origen, nacional-socialismo

\begin{abstract}
This paper aims to compare the ontologies developed by Heidegger and Cassirer and shows that the two philosophers have different conceptions about the origin of the multiple senses of being, which are used to support opposite interpretations concerning the raise of the national-socialism in Germany. Heidegger sees the sense of being as coming from one single origin: whether it be the temporality of Dasein (in the texts around Being and Time) or the epocality of Being (in the later Heidegger). Cassirer, otherwise, considers Being as given from a multiplicity of origins, which are expressed in the symbolic forms of culture (art, religion, science, etc.). Curiously, both philosophers will use their respective ontologies to interpret the event of National Socialism comparing the relation between myth and technology. So, in the early 1930s Heidegger conceives his history of being (Geschichte des Seins) from a mythopoetic perspective and sees the national-socialism as a possibility of returning to the Greek beginning of the occidental thinking and as the irruption of another way of Being that could overcome the technological world domination. Cassirer, on the other side, understands the Nazism as an undue influence of myth over the technical-scientific society.
\end{abstract}

Keywords: Heidegger, Cassirer, ontology, origin, national socialism

O objetivo desse artigo é comparar as ontologias de Heidegger e Cassirer e mostrar como ambas foram utilizadas pelos dois filósofos para sustentar posições diametralmente opostas acerca da ascensão do nacional-socialismo na Alemanha. Essa comparação não é gratuita, Cassirer e Heidegger são herdeiros de certa tradição neokantiana e fenomenológica, partem de problemas ontológicos semelhantes e travam diálogos em torno de temas centrais da filosofia. Entretanto, apesar de partirem de problemas semelhantes, nossos filósofos irão elaborar 
ontologias distintas. Acreditamos que o ponto fundamental que separa as ontologias dos dois filósofos diz respeito ao problema da origem, tema central do debate ocorrido em Davos. Em Heidegger a compreensão do ser é pensada, de maneira sempre crescente, a partir de uma origem única e em um horizonte único de sentido. Cassirer, por sua vez, pensa o ser a partir de uma multiplicidade de aberturas de sentido que se perfazem no desenvolvimento cultural do serhumano. Tentaremos mostrar que, embora não exista propriamente uma filosofia política nem em Heidegger e nem em Cassirer, ontologias distintas servirão para fundamentar diferentes posições políticas. Curiosamente, os posicionamentos políticos de ambos os filósofos são elaborados mediante uma comparação entre mito e técnica.

Assim, no início dos anos de 1930 Heidegger vê a possibilidade de unir ontologia e nacionalsocialismo a partir de uma "estrutura mito-poética” subjacente à sua concepção de história do ser (Seinsgeschichte) que começa a ser desenvolvida nesse período e é por ele mesmo explicitada na obra Introdução à Metafísica. Cassirer, por sua vez, verá a ascensão do nazismo como a irrupção indevida da função mítica em meio a sociedade técnico-científica da Alemanha no início da década de 1930.

\section{Heidegger e a origem mito-poética da história do ser}

Primeiramente, faremos uma breve análise da noção de historicidade no quadro teórico da ontologia fundamental a fim de chegar à noção de verdade do ser tal qual surge no início dos anos de 1930 e justificar a tese de uma mitologia da origem nessa fase do pensamento de Heidegger. Em seguida analisaremos o projeto de uma filosofia das formas simbólicas de Cassirer, comparando-a com a ontologia heideggeriana, e mostrando como a relação entre as funções simbólicas do mito e da tecnociência é usada para explicar o surgimento do nazismo na Alemanha.

Como se sabe, nos textos do entorno de Ser e Tempo, a pergunta pelo sentido de ser deve ser precedida por uma analítica existencial da finitude humana enquanto âmbito a partir do qual o ser é compreendido. Heidegger se utiliza do termo ser-aí (Dasein) para designar a existência humana enquanto lugar da compreensão do ser e, ao mesmo tempo, para desconstruir as concepções tradicionais que buscam pensar o humano no quadro da categoria tradicional do ser como substancialidade ou subsistência (Vorhandenheit). O ser-aí não é um ente substancial com propriedades definidas, mas puro poder-ser, pura possibilidade de sentido que, devido a sua essência temporal e finita, nunca se completa e nunca possui a posse definitiva de si mesmo.

Com isso, a analítica da existência torna-se uma ontologia fundamental que busca pôr a descoberto a temporalidade (Zeitlichkeit) do ente humano como horizonte transcendental para a pergunta pelo sentido de ser. A temporalidade projeta o ser-aí em direção ao mundo, ou seja, à totalidade de sentido na qual os entes são compreendidos mediante determinados modos de ser, possibilitando todo o comportamento humano em relação às coisas e aos outros seres humanos. Toda compreensão de ser e, consequentemente, todo modo de acesso aos entes, é sempre uma possibilidade de ser do ser-aí e remete, em última instância, ao caráter projetivo (Geworfenheit) de suas êxtases temporais, as quais modulam as possibilidades de existência do ser-aí.

O acesso à temporalidade originária se dá mediante um processo de singularização no qual o ser-aí, tomado pela angústia, percebe-se como ser finito e livre para morte e, rompendo com a medianidade cotidiana, apropria-se das possibilidades de ser herdadas da tradição à qual ele pertence. Desse modo, em Ser e Tempo, a assunção angustiante da morte, denominada de resolubilidade (Entschlossenheit), é a condição de possibilidade do agir próprio ou autêntico (eigentlich), no qual o ser-aí transmite a si mesmo (Sichüberliefern) uma possibilidade de ser na qual já se encontra lançado e conquista seu destino (Schicksal). Essa apropriação de um 
sentido de ser historicamente herdado constitui a historicidade própria do ser aí, o acontecer da comunidade, do povo, que lhe permite "ser para o seu tempo", "escolher os seus heróis”, etc.

Assim, podemos dizer que em Ser e Tempo, a historicidade constitutiva da temporalidade do ser-aí é o que lhe permite apropriar-se de sua história e projetar o seu futuro. Entretanto, no início dos anos trinta, Heidegger introduz uma nova noção de historicidade que já não é simplesmente constitutiva da temporalidade, mas que deve ser instaurada mediante uma ação decisiva (entscheidende) que inaugura o primeiro início do pensamento ocidental e põe em marcha a história do ser. A noção de resolubilidade (Entschlossenheit), que em Ser e Tempo permitia ao Dasein apropriar-se de sua história, é substituída por uma decisão (Entscheidung) que coloca o ser-aí em sintonia com a força desse início. Essa ideia de uma historicidade originária que, ao contrário de Ser e Tempo, não é apenas constitutiva da existência do ser-aí, mas que deve ser instaurada a partir de um ato de decisão (Entscheidung), é um dos elementos que permeiam a noção de verdade do ser à época do engajamento político de Heidegger com o nacional-socialismo. Um dos lugares onde se faz ver esse caráter mitológico e político da verdade do ser é curso de 1935, Introdução à Filosofia.

Nessa obra, o início historial do povo grego, cuja força marca o destino do ocidente e inaugura assim denominada "história do ser", é visto como um acontecer primordial, uma $U r$ geschichte, que não pode ser explicada mediante um estudo historiográfico ou antropológico do passado. A história originária não é acessível a nenhuma ciência positiva, mas só pode ser “compreendida” na medida em que nos vinculamos a ela e somos capazes de projetar a força desse primeiro início no futuro. Isso faz com que o acesso a essa história seja, em certo sentido, mitológico:
A inexplicabilidade (Unerklärbarkeit) desse início não é nenhuma falta ou fracasso do nosso conhecimento da história. Na compreensão do caráter misterioso desse início repousa, antes, a autenticidade (Echtheit) e a grandeza do conhecimento historial (geschichtliches Erkennen). Saber sobre uma história originária não é nem escavar o primitivo nem recolher ossos. Não é nem meia nem toda ciência da natureza, mas, se acaso for algo, é Mitologia (Mythologie) (GA 40, p. 164-5).

A referência ao mitológico visa introduzir uma temporalidade originária que não é aquela do tempo linear das ciências positivas, mas que também vai além da Zeitlichkeit tal qual exposta em Ser e Tempo. O mito não se encontra no passado mas, uma vez desoculto o poder que ele abriga, projeta o ser humano em direção a possibilidades futuras, instaurando um novo início e forjando o destino de um povo.

Assim, o início historial do povo grego, cuja força marca o destino do ocidente, é visto como o acontecer da irrupção violenta do humano em meio ao ente na totalidade. A instauração desse início se perfaz como uma ação violenta (gewalt-tätig) e decisiva (entscheidend) que abre um espaço do ser em meio à supremacia avassaladora e terrível do ente na totalidade. Para conformar o ente em seu ser, para dizer o que o ente é, o homem precisa tornar-se ele mesmo o que há de mais terrível e avassalador. O surgimento da história do ser revela-se, ao mesmo tempo, como ato político, na medida em que a polis grega é “o estado-historial (Geschichtsstätte), o aí (das $\mathrm{Da}$ ) no qual, desde o qual e para o qual acontece história (Geschichte geschieht)” (GA 40, p.162). Os atores políticos dessa ação violenta e instauradora, desde a qual a história do ser acontece, são os poetas, os pensadores, os sacerdotes e os homens de estado. Esses cidadãos da polis seriam atores violentos (Gewalt-tätige) na medida em que decidem "utilizar de violência e tornar-se elevados no ser historial como atores (Täter) e criadores (Schafende)" (GA 40, p. 162).

É importante deixar claro aqui que esse ato instaurador não implica em nenhuma violência física. As violências, do projetar pensante, do edificar edificante, do agir estatizante, são antes possibilitadas por um dizer desocultador que reúne e condensa o ente em seu ser e que se revela de modo eminente no dizer poético (Dichtung), o qual inaugura a história do ser e traça o destino 
do pensamento ocidental. Há aqui uma simultaneidade entre o surgimento de uma língua e da história de um povo, na medida em que a linguagem é apropriada pelo poder sobrepujante da revelação do ser do ente na totalidade:

A linguagem apenas pode começar a partir daquilo que é avassalador e extraordinário, na irrupção do homem no ser. Nessa irrupção (Aufbruch) a linguagem era o tornar-se-palavra do ser (Wortwerden des Seins): poesia (Dichtung). A linguagem é a poesia originária (Urdichtung), na qual um povo poetisa o ser. Inversamente, a grande poesia, pela qual um povo entra na história, dá início à formação da sua língua (GA 40, p. 180).

Assim, no início do pensamento ocidental, “em razão de uma experiência poético-pensante

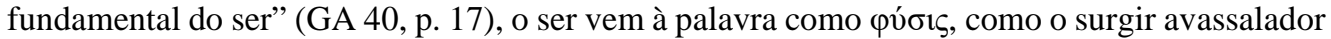
do ente na totalidade, cuja revelação poética abre ao ser-aí sua própria historicidade e inaugura a metafísica ocidental como história do ser. Seriam os poetas e os pensadores gregos aqueles que inaugurariam e conservariam a força desse início que projeta o destino do povo grego e do ocidente.

E aqui Heidegger parece padecer de uma ideia de progresso às avessas. A força violenta do início grandioso (der grosse Anfang) da história do ser (que não provém do homem, mas do próprio ser) diminui na medida em que o homem, tomado pelo encanto da revelação do ente, esquece-se do ser. Assim, a história do ser adquire um caráter epocal, cujas etapas são intimamente aparentadas enquanto respostas possíveis ao chamando do ser, ao mesmo tempo em que são marcadas por um crescente abandono ou esquecimento do ser. A metafísica ocidental passa a ser caracterizada como a história do esquecimento do ser, na qual o ser revelase enquanto entidade do ente e, ao mesmo tempo, retrai-se enquanto ser ele mesmo. Esse esquecimento do ser se inicia desde cedo no pensamento ocidental quando os gregos caracterizam o ser-humano como "animal que possui o logos" - fazendo da linguagem um instrumento e uma propriedade do ser-humano e não um vínculo ao poder avassalador

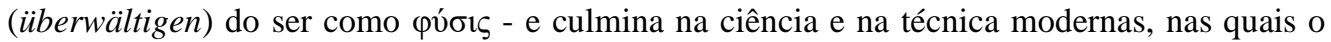
$\lambda$ óyos torna-se a razão instrumental que visa o cálculo incondicional de tudo que existe e a história do ser esgota suas possibilidades. O fim dessa história se realiza, embora ainda não tenha se consumado, na maquinação (Machenschaft) como a incondicional habilitação ao poder através da determinação de fins e valores e do domínio técnico sobre os entes, cujo resultado é o cálculo e a planificação de tudo que existe - inclusive do próprio homem - visto agora como mais um elemento - ainda que o mais nobre - da técnica. Assim, no início, a linguagem possui o ser humano e surge como uma resposta ao apelo do ser que exige ser trazido à palavra abrindo o ente na totalidade como púఠıc. No fim o ser humano é visto como possuidor da linguagem, a qual torna-se um mero instrumento da maquinação:

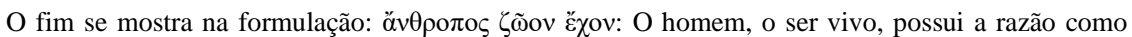
equipamento. O início nós compreendemos em uma formulação livremente construída, que ao mesmo

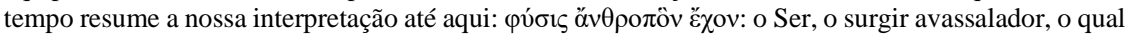
exige (ernöten) o reunir que possui o ser-humano (acusativo) e o fundamenta (GA 40, p. 184).

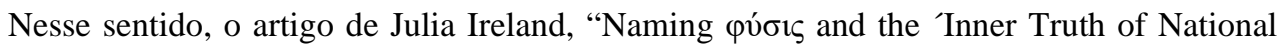
Socialism'”, parece reforçar a tese de que a estrutura mito-poética da história do ser está diretamente ligada à narrativa que Heidegger utiliza para fundamentar sua adesão ao nacionalsocialismo. $\mathrm{O}$ artigo é baseado em um profundo trabalho de arquivo que procura discutir o lugar da controversa frase de Heidegger acerca da "verdade interna" do movimento nacional socialista, expressa na Introdução à Metafísica, a qual ela descobriu também estar presente na versão original manuscrita dos cursos sobre os hinos de Hölderlin, "Germania” e “o Reno" (GA39), proferidos no semestre de 1934/35, fato esse que estabelece uma nova relação entre os dois textos. 
Com efeito, Heidegger justifica a escolha de Hölderlin para falar de poesia pelo fato de ele ser ao mesmo tempo poeta dos poetas, em cujos poemas se realiza a essência da poesia, e poeta do povo alemão. Com isso, retoma a ideia de uma origem mito-poética da história de um povo e, ao mesmo tempo, aponta para seu caráter político.

Porque Hölderlin é esse encobrimento e essa dificuldade, poeta dos poetas e poeta dos alemães, por isso ele ainda não se tornou o poder na história do nosso povo. Por ainda não ser, deve tornar-se. Tomar parte nisso é "política” em um sentido mais elevado e originário, tanto que, quem aqui conquista algo, não tem necessidade de falar do “político” (GA 39, p. 214).

Como se sabe, Heidegger interpreta a frase final do poema Andenken (rememoração) de Hölderlin, "aquilo que permanece, fundam os poetas”, como sendo um dos lugares onde estaria dito que os poetas instauram (stiften) o Ser (Seyn). A palavra Seyn, escrita de modo arcaico, indica o ser pensado como acontecimento criativo que abre o ente na totalidade para o Dasein humano e inaugura a história de um povo. Isso se explica nos dois sentidos atribuídos à palavra instaurar (stiften): 1) enquanto aquilo que ainda não é, mas deve ser projetado em sua essência no dizer poético e 2) como rememorar poético (Andenken) que conserva e protege a essência do aberto e permite que seja pensado de modo novo: "O ser assim fundado no poema abarca sempre o ente na totalidade: os deuses, a terra, os homens e esses em sua história, ou seja, o povo.” (GA 39, p. 215). Um exemplo desse modo de instauração são os poemas de Sófocles, nos quais a experiência grega da púбıৎ vem à palavra.

Ao dizer que Hölderlin ainda não é, mas deve tornar-se um poder na história do povo alemão, Heidegger parece lançar uma tarefa política, no sentido originário aqui exposto. Como bem

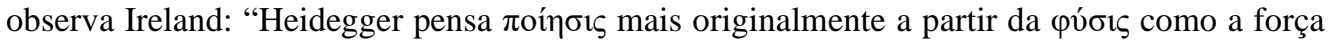
nominante (naming force) que não apenas inaugura 'outra metafísica', mas também outra 'política'” (Ireland, 2014, p. 332). O que estaria em jogo nesse projeto poético-político seria a abertura de uma experiência poética do ser que possibilitasse o surgimento de um outro começo para o povo alemão a partir da rememoração criativa do primeiro começo grego que deu origem à metafísica ocidental.

Entretanto, essa nova experiência do ser não deve ser pensada como um retorno à pv́бıs, cujas possibilidades se esgotaram no desenvolvimento histórico da metafísica ocidental que culmina no domínio técnico-científico do ente. "Hölderlin não é o helenismo mas o futuro dos alemães” (GA 39, p. 255) e esse deve ser projetado por uma “outra metafísica, ou seja, por uma nova experiência fundamental do ser” que "deve ser mais originária que aquela dos gregos, que

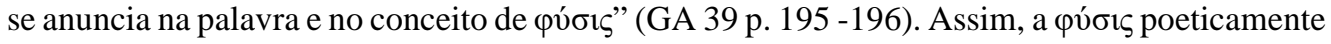
pensada servirá tanto para Heidegger desconstruir a velha metafísica quanto para abrir caminho para uma outra experiência do ser.

É precisamente no contexto de uma crítica a fase final da metafísica como domínio da técnica que se situa a referência à "verdade interna do nacional-socialismo”. Ireland, mediante uma análise cuidadosa (que não cabe aqui reproduzir) do local onde essa polemica frase de Heidegger aparece, tanto em Introdução à Metafísica quando nos cursos sobre Hölderlin, mostra que a frase aponta para uma crítica tanto à ciência acadêmica, que na época da Macheschaft se transformara em "negócio organizado (Betriebe) de aquisição e compartilhamento de conhecimento", quando à "nova” ciência defendida pelos nazistas, a ciência alemã, baseada no conceito biológico de povo e de raça e nas ideias de valor e heroísmo. Ambas seriam parte da desnaturalização da púoıs que caracteriza o crescente processo de esquecimento do ser no pensamento ocidental, e não teriam nenhuma relação com a "verdade interna do nacional-socialismo". Verdade essa que, ao que tudo parece indicar, deveria ser guiada por uma política baseada em um projeto mito-poético de fundação de um povo, certamente desconhecido pelos nazistas. Como muito já se falou a respeito, Heidegger possui uma visão muito própria do nacional-socialismo, um “nacional-socialismo espiritual” (GA 94, 
p. 135) que não encontra ressonância no nacional-socialismo real, partidário. Assim, Heidegger parece desenvolver um conceito poético-político de povo que não está baseado na noção biológica de raça.

Não há espaço aqui para discutir se, como sugere Peter Trawny, a noção historial de povo em Heidegger não exclui um conceito de raça ${ }^{1}$. O fundamental para os nossos propósitos (e nisso concordamos com Trawny) é o fato de que o engajamento de Heidegger com o nacionalsocialismo só se torna compreensível “a partir da narrativa de um 'primeiro início' com os gregos um ‘outro início’ com os alemães” (Trawny 2014, p. 28), tendo a técnica como fase final que ainda não se consumou.

Essa "narrativa que une dois inícios e um fim, caracterizado como maquinação” (Trawny, 2014, p. 22), está presente nos textos onde Heidegger justifica a assunção do cargo de reitor durante o regime nacional socialista e é a base do Discurso do Reitorado. Então, o nacionalsocialismo surgia como uma oportunidade de superação do esquecimento do ser e de instalação de um novo início para o povo alemão mediante o retorno a uma vontade que teria se manifestado no início do pensamento grego quando "pela primeira vez o homem ocidental, a partir do caráter de um povo, por força de sua língua, ergue-se diante do ente em sua totalidade e o interroga e o concebe como ente que ele é” (Heidegger, GA 16 p. 109)². Em tal início estaria o sentido originário da ciência grega (que fora esquecida pelo pensamento metafísico e técnicocientífico do ente), cuja força e grandeza não se encontrariam perdidas em algum lugar do passado, mas estariam à frente do Dasein historial, apontando para o seu futuro. Essa ciência originária não se confunde, como vimos, nem com a ciência moderna nem com a "nova” ciência nazista: "Ciência é apenas o modo rigoroso e, com isso, responsável daquele conhecimento que o povo todo busca e exige para a verdade e duração do seu Dasein historial” (GA 16, p. 305).

Heidegger buscava, então, um saber que poderia atrelar-se à força desse primeiro começo. Seria apenas unindo-se a esse saber originário que o povo alemão, através da união entre os serviços do trabalho, o serviço militar e o serviço do saber (Arbeits-, Wehr- und Wissensdienst), poderia compor uma única força capaz de superar a técnica moderna marcada pela exposição desprotegida do homem em meio ao ente. Heidegger atribuía um caráter revolucionário ao nacional-socialismo, por ver nele a possibilidade de irrupção de um novo início para a Alemanha e para o ocidente, na qual a universidade como o local do saber desempenharia um papel central nesse projeto político:

Podia-se em toda parte saber o que eu pensava acerca da universidade e o que eu supunha como o seu interesse mais iminente. Ela deveria renovar-se a partir de sua essência fundamental, que também é a essência da ciência, a saber, a partir da essência da verdade mesma e, ao invés de insistir na aparente unidade técnica organizatória e institucional, deveria reconquistar a unidade viva daqueles que questionam e conhecem (GA 16, p. 373).

Assim, Heidegger assume o cargo de reitor na universidade de Freiburg acreditando no regime nacional-socialista como uma possibilidade de reabilitação da essência da universidade e das ciências, fragmentadas pela divisão técnica em disciplinas, através de uma ação política que possibilitasse o retorno à primeira origem do pensamento ocidental. Em um discurso de 1934, após ter deixado o cargo de reitor, Heidegger vincula a reforma universitária à conquista do "Dasein espiritual do povo alemão" pela qual poderia ser exercida a verdadeira educação e através da qual não apenas a Alemanha, mas junto com ela a Europa, poderiam encontrar a autêntica união e paz duradouras:

Através da educação, o povo chega à responsabilidade própria. Mas povos autoresponsáveis são as únicas e mais elevadas garantias da paz; pois a responsabilidade própria compromete-se a si mesma

\footnotetext{
Sobre isso ver Trawny, 2014, p. 59 ss.

Tradução de Fausto Castilho (Heidegger, 1997a, p. 4).
} 
com o valente cuidado do outro e exige de si mesma a honra incondicional do outro [...] Assim, a comunidade dos povos já não necessita ser erigida através de uma liga, mas já está aí originariamente e de modo duradouro (GA 16, p. 307).

E aqui se revela um dos aspectos do caráter mítico da história do ser, que discutiremos de modo mais detalhado adiante, a partir de Cassirer. Heidegger sugere que o retorno criativo à origem do pensamento ocidental, à verdadeira essência da ciência, possibilitaria unidade orgânica não apenas do corpus acadêmico, mas da Europa como um todo, dispensando qualquer forma de unidade institucional.

Felizmente sabemos que essa crença no nacional-socialismo como meio de transição para um outro começo dura pouco. Se no ensaio sobre a Origem da Obra de Arte Heidegger ainda via na instituição de um estado um modo destacado de essencialização da verdade do ser, a partir de 1936 ele começa a ver toda saída política e institucional como mais um modo da maquinação. O estado nazista e a própria figura do Führer passam a ser vistos agora como uma das facetas mais extremas da técnica, como uma consequência necessária da errância (Irre) que caracteriza a época do ser no fim da metafísica, "que exige uma única ordem e o controle do ente e propaga o vazio” (GA 7, 91).

Essa mudança de posição em relação ao nacional-socialismo, na segunda metade dos anos de 1930, leva alguns autores, como Silvio Vietta, a ver aqui uma ruptura com o regime ${ }^{3}$. Entretanto, a publicação recente dos cadernos negros parece mostrar que, se Heidegger rompe e se desilude com o nacional-socialismo "real”, ele parece manter a crença na verdade "interna desse movimento", ainda que por outros motivos, como parece confirmar a seguinte passagem dos Cadernos Negros dos anos de 1938-39:

\begin{abstract}
Pensando de modo puramente metafísico (ou seja ontológico-historial) tomei o nacional-socialismo, nos anos de 1930 - 1934, como a transição (Übergang) para um outro início e lhe dei esse significado. Com isso esse "movimento" foi desconhecido e subestimado em suas forças autênticas e em suas possibilidades internas, bem como em sua dimensão e excelência próprias. Aqui se inicia antes o fim da modernidade de um modo mais profundo - ou seja mais abrangente e penetrante do que no fascismo (GA 95, p. 408).
\end{abstract}

Heidegger admite ter cometido um erro ao pensar o nacional-socialismo como uma transição, mas isso seria apenas um engano que desconhece a força de sua verdade interna. Esta não estaria no fato de o movimento ser uma transição, mas antes uma consumação do fim da modernidade como maquinação. Assim:

Apenas a partir da visão completa desse engano sobre a essência e a força historial do nacionalsocialismo surge a necessidade de sua aceitação (Bejahung), e isso a partir de razões de pensamento (aus denkerischen Gründen) (GA 95, p. 408).

Trawny identifica aqui duas fases da relação de Heidegger com o nacional-socialismo, a saber: como movimento revolucionário para um outro início e como um modo final da maquinação, necessário para um corte na história do ser (Trawny, 2014, p. 30). Seja como for, a narrativa mito-poética de um primeiro início, cuja força pode ser acessada e projetada no futuro permanece talvez de modo até mais absoluto após o rompimento de Heidegger com o nacional-socialismo “real”. Assim, a história do ser nivela e arrasta consigo tudo o que nela se

\footnotetext{
Segundo Vietta: "Heidegger desenvolve, assim, sua crítica ao fascismo sobre um plano que permite antes de tudo perceber nesse movimento, para falar como Dahendorf, um impulso da dominação, ou seja, a empresa formidável e crescente de um sistema totalitário infiltrando todos os domínios da vida - e, nesse sentido, "gigantesco" - assim como a objetivação (Vergegenständlichung) do mundo tornada possível pelo pensamento sistemático, racional e moderno, e a tecnologia especificamente moderna que é constituída sobre a base desse pensamento” (Vietta, 1993, p. 84).
} 
encontra, tornando-se impossível, no Heidegger tardio, diferenciar campos de extermínio de indústria armamentista (GA 79, p. 27), nazismo de social democracia (GA 16, 375).

Procuramos mostrar até aqui que no pensamento de Heidegger a pergunta pelo ser é pensada a partir da necessidade de buscar uma origem única para a abertura de sentido, a partir da qual são articulados os diversos modos de encontro humano com as coisas. No assim denominado primeiro Heidegger, essa abertura é a temporalidade do ser-ái. No Heidegger dos anos de 1930 ela é pensada a partir das doações epocais do ser ele mesmo que surgem do primeiro início grego.

Gostaria de fazer um contraponto a esse modo de pensar o ser, focado em uma origem única e em um horizonte único de sentido, mediante uma rápida explanação do projeto de uma filosofia das formas simbólicas de Cassirer.

\section{Cassirer e as formas simbólicas}

No primeiro volume de sua "filosofia das formas simbólicas", escrito cinco anos antes de Ser e Tempo, Cassirer afirma que a filosofia se inicia com a pergunta pelo ser e que unidade do ser teria sido tradicionalmente concebida a partir da unidade da substância. Consequentemente, o ser fora sempre pensado a partir de um determinado ente tomado como o fundamento a partir do qual todas as relações possíveis entre os demais entes pudessem ser deduzidas geneticamente. (Cassirer, 2010a, p. 1) Essa hipóstase de um determinado ente ou domínio ôntico encobriria um conceito mais fundamental de ser, latente em todo idealismo ocidental desde Platão, que teria sido explicitado pela primeira vez com o pensamento crítico de Kant. Assim, na Crítica da Razão Pura, o conceito de substância é visto como pertencente à função sintética do entendimento. Todo conhecimento teórico só é possível devido aos conceitos ou categorias do entendimento que relacionam e ordenam diversas representações dadas na intuição sob uma representação comum, constituindo a objetividade da natureza. Desse modo, o idealismo transcendental de Kant já revelaria uma precedência do conceito de função sobre o conceito de substância. Tal precedência não se restringe apenas ao conhecimento teórico, ou seja, físico matemático da natureza. Seria uma consequência natural da filosofia de Kant que o pensamento crítico fosse estendido aos demais domínios da realidade, ao campo da moral, da estética e da vida, nos quais, a cada vez, uma determinada faculdade humana exerce uma função legisladora e ordenadora.

Porém, para Cassirer, pensar a constituição dos diversos domínios do ser a partir do jogo entre as diversas faculdades humanas (razão, entendimento, intuição, imaginação, etc.), como faz Kant, seria incorrer ainda em um erro metafísico que consiste em eleger um determinado domínio ôntico como origem a partir da qual toda forma de objetividade pudesse ser deduzida geneticamente. "O ser”, diz Cassirer, "não pode aqui ser compreendido em nenhum outro lugar senão no fazer (Tun).” (Cassirer, 2010a, p. 9). Seria nas obras da cultura humana ou, para usar um conceito emprestado de Hegel, seria nas diversas manifestações do espírito objetivo (arte, religião, linguagem, mito, ciência, etc.), que se constituem os diversos domínios do ser.

Arte, religião, linguagem, mito, ciência são agora pensadas como formas simbólicas: “não no sentido de que designam na forma de imagem, na alegoria indicadora e explicadora, um real existente, mas sim, no sentido de que cada uma delas gera e parteja seu próprio mundo significativo" (Cassirer, 2009a, p. 22). As formas simbólicas não são representações de uma realidade ou coisa em si que possuísse uma existência autônoma. Elas constituem a própria dimensão significativa no interior da qual as coisas unicamente podem existir para nós. Elas são as condições de possibilidade de toda objetividade, de todo mundo humano dotado de sentido.

“Com isso a Crítica da Razão Pura torna-se crítica da cultura” (Cassier, 2010a, p. 9), pensada como uma fenomenologia das formas simbólicas. Cada uma das formas simbólicas é 
uma unidade de sentido autônoma e possui um ponto de vista (Blickpunkt) próprio a partir do qual é constituído seu domínio objetivo. Nenhuma dessas unidades de sentido pode ser reduzida às outras ou explicada pelas demais. Segundo uma interpretação mais ampla da conhecida revolução copernicana de Kant, o conhecimento humano não consiste na adequação a uma realidade previamente dada, mas, ao contrário, toda realidade, todo domínio objetivo, seja ele “empírico” ou "ideal” é constituído a partir de uma função geral do espírito, manifesta nas formas simbólicas da cultura, que consiste em ordenar e relacionar uma multiplicidade a partir de um sentido comum: arte nos dá uma unidade de intuições, a ciência de pensamentos e o mito e a religião de sentimentos. A arte nos abre um universo de formas vivas, a ciência um universo de leis e princípios e a religião e o mito a percepção da identidade universal e fundamental da vida.

Entretanto, apesar de toda formação simbólica ser uma unidade autônoma de sentido, com uma função sintética própria, elas não existem isoladas umas das outras. Toda forma simbólica se encontra em uma relação com as demais, sem que uma seja superada ou eliminada pelas outras. A tarefa da filosofia seria pensar as diversas formas simbólicas ao mesmo tempo em sua autonomia e interdependência, em seus princípios constitutivos e em seu mútuo condicionamento, buscando estabelecer um vínculo entre elas:

Linguagem, mito, arte e religião não são criações isoladas, aleatórias. Estão unidas por um vínculo comum. Mas esse vínculo não é um vínculum substantiale, como foi imaginado e descrito pelo pensamento escolástico, mas um vinculum functionale. É a função básica da fala, do mito, da arte e da religião que devemos buscar por trás de suas inumeráveis formas e expressões, e para qual em última instância devemos buscar uma origem comum (Cassirer, 1992, p. 68).

Cassirer tenta expor essa unidade funcional estabelecendo uma tipologia das diferentes funções simbólicas, dividindo-as em 1) expressiva (Ausdrucksfunktion) 2) representativa (Darstellungsfunktion) e 3) significativa (Bedeutungsfunktion).

A dimensão expressiva é considerada a mais originária e primeira, nela o símbolo se encontra incorporado em um objeto sensível no qual se revela imediatamente uma vida interior. Na função expressiva do símbolo, as coisas aparecem para nós em seu caráter fisionômico, ou seja, elas são dotadas de qualidades afetivas, mostrando-se como acolhedoras ou ameaçadoras, prazerosas ou desconfortáveis, etc., revelando-se em sua e mútua permeabilidade, em seu caráter "simpático”, no qual se expressa a unidade indissolúvel da vida. A função expressiva está na base do mito e, em certa medida, da arte.

Diferentemente da dimensão expressiva, na qual as coisas são tomadas em sua fluidez e permeabilidade, na função representativa do símbolo as coisas são pensadas como substâncias isoladas com propriedades determinadas. O caráter representativo das formas simbólicas subjaz à nossa linguagem cotidiana e orienta a nossa lida prática no mundo. Essa função está na origem da lógica clássica e tem sua forma mais pura e característica no "ser” da cópula, perdurando desde a antiguidade até a modernidade.

Entretanto, é no seio da modernidade que se constitui uma nova função do símbolo, a função significativa. Nela as coisas são vistas em sua pura relação e perdem sua substancialidade. A dimensão significativa começa a se configurar com moderna ciência matemática e tem sua primeira expressão com o cálculo infinitesimal de Leibniz. Mas é no desenvolvimento da lógica matemática do século vinte que essa função alcança sua forma mais acabada. A dimensão representativa do símbolo, manifesta na mera notação (Zeichen), "não expressa nada nem representa nada, ela é pura notação no sentido de uma ordenação (Zuordnung) meramente abstrata”, na qual o símbolo se livra de toda intuição e "paira no éter livre do puro pensamento" (Cassirer, 2009, loc. 1256).

Para Cassirer esse desenvolvimento das formas simbólicas não implica na substituição e na superação de uma forma por outra. As funções mais originárias e básicas coexistem com as mais 
“elevadas” e até mesmo habitam no interior daquelas formas que as sucederam. Não há aqui uma subsunção de uma forma por outra com as figuras do espírito de Hegel, a relação entre as diversas funções simbólicas é mais trágica do que dialética: ciência, mito, arte e religião, podem encontrar-se em harmonia, mas na maioria das vezes sua relação é conflituosa.

E aqui nos deparamos com um aspecto problemático da filosofia de Cassirer. Embora as diferentes formas simbólicas sejam unidade de sentido autônomas e coexistam sem que uma elimine ou supere as outras, em alguns momentos Cassirer parece atribuir um caráter teleológico e uma certa hierarquia em seu sistema das formas simbólicas. Assim, em um de seus últimos escritos (Um ensaio sobre o homem) ele afirma que a ciência matemática é "a última etapa do desenvolvimento mental do homem", podendo "ser vista como a mais alta e mais característica façanha da cultura humana”. (Cassirer, 2001, p. 337) É na lógica matemática que se revela o caráter funcional do espírito que subjaz a todas as demais formas simbólicas, pois:

o que nela é estabelecido (festhalten) é uma relação e uma correspondência mútua, que é apreendida em sua lei geral quando nós renunciamos a tomar representativamente os elementos que entram nessa relação como substâncias autossuficientes (als selbständiger Bestand), como conteúdos que ainda seriam ou significariam algo fora dessa relação (Cassirer, 2009b, loc. 1255-60).

É justamente a partir dessa tipologia das formas simbólicas e seu caráter teleológico que se desenvolverá as análises de Cassirer sobre o mito e sua discussão com Heidegger.

\section{Mito e espacialidade}

Um bom caminhão para compreendermos o debate de Heidegger e Cassirer sobre o mito é pela discussão que ambos travam acerca do espaço, devido à semelhança entre a caracterização do espaço mítico no segundo volume da Filosofia das Forma Simbólicas e a espacialidade cotidiana do Dasein em Ser e Tempo. Para os nossos propósitos não cabe aqui uma análise mais detida do espaço mítico e do espaço cotidiano, mas apenas destacar alguns aspectos comuns entre elas.

Como não poderia deixar de ser, as considerações de Cassirer sobre o espaço mítico obedecem à lógica da sua tipologia das formas simbólicas:

E aqui primeiramente se mostra algo decisivo para nossa consideração: que não há uma intuição geral e simplesmente fixa do espaço, mas sim que o espaço obtém seu conteúdo determinado e sua tessitura (Fügung) própria apenas da ordenação de sentido (Sinnordnung), no interior da qual ele a cada vez se conforma. Cada vez que ele é pensado segundo uma ordenação mítica, estética ou teórica, muda-se também a "forma” do espaço - e essa mudança não toca apenas seus traços isolados ou subordinados, e sim a sua totalidade, a sua estrutura principal. O espaço não possui uma estrutura simplesmente dada e definitivamente fixa, mas ele antes conquista essa estrutura apenas graças a um nexo de sentido geral (allgemeinen Sinnzusammenhangs), no interior do qual sua edificação se realiza. A função de sentido é o momento primeiro e determinante, a estrutura do espaço é o momento secundário e derivado (Cassirer, 2009, loc. 2195).

Segundo Cassirer, o espaço mítico deve ser compreendido a partir da função expressiva do mito na qual as valorações afetivas do mundo são transpostas espacialmente. Ao contrário do espaço homogêneo da geometria, no espaço intuitivo mítico cada lugar e cada direção é igualmente dotado de um sentimento valorativo, cuja primeira divisão se expressa na distinção entre o espaço sagrado e o profano. Ao contrário do espaço geométrico - no qual os diversos pontos que o compõe são esvaziados de todo conteúdo e indiferentes ao lugar que eles ocupam - no espaço mítico, ao contrário, não há separação entre o lugar de uma coisa e seu conteúdo, o local onde algo se encontra é parte integrante do seu ser. Assim, as diversas regiões do espaço mítico são qualitativamente divididas, o “em cima” e o “embaixo” podem, por exemplo, 
corresponder ao sagrado e o profano. Do mesmo modo, a distância entre as coisas não pode ser pensada como mesurável e quantificável no sentido do espaço teórico, mas mediante uma relação de afinidade entre elas que é dada por um sentimento de identidade orgânica entre seus elementos. "Por força desse princípio peculiar do pensamento mítico a distância espacial é constantemente negada e excluída dele. O mais longe converge com o mais perto, na mediada em que esse se espelha naquele" (Cassirer, 2010b, p. 108). Assim o perto e o longe, o aqui e o ali, não são simples termos de uma relação geral que pode ser aplicada a conteúdos diferentes, como no espaço teórico, mas antes modos de afinidade entre as coisas que, no limite, exclui toda distância mensurável. A unidade do espaço mítico não é uma unidade de leis e relações abstratas aplicáveis a qualquer objeto em geral, mas ela é antes dada pelo fato de seus elementos estarem fundidos (verschmelzen) em um mesmo todo significativo que os precede.

Existem algumas semelhanças entre o espaço mítico descrito por Cassirer e espacialidade (Räumlichkeit) cotidiana do Dasein em Ser e Tempo. Como se sabe, Heidegger pensa a espacialidade originária a partir da análise do ente instrumental (Zeug), desenvolvida no parágrafo 15 de Ser e Tempo, cujo modo de ser é o ser-à-mão (Zuhandenheit), visando com isso desconstruir a noção cartesiana de mundo como res extensa, como um lugar no qual as coisas se encontram no modo da Vorhandenheit: enquanto entes simplesmente dados, como unidades substanciais autônomas com qualidades determinadas. Assim, ao contrário da visão cartesiana, nosso contato primeiro com as coisas se daria no uso de instrumentos na nossa lida cotidiana. Quando utilizamos um instrumento qualquer não o pensamos como um ente isolado, mas só podemos apreendê-lo a partir de um todo instrumental (Zeugganzen) previamente dado no qual se insere. $\mathrm{O}$ olhar com que apreendemos um instrumento dentro de um nexo instrumental (Zeugzusammenhang) não implica uma apreensão teórica do que é dado, e sim uma circunvisão (Umsicht) que caracteriza toda orientação prática sobre as coisas de que fazemos uso em nossa lida cotidiana. A análise do ente instrumental mostra o mundo como uma cadeia de significações na qual está sempre em jogo, em última instância, a existência do Dasein como um todo.

Assim, as coisas só podem ser dadas no modo da Vorhandenheit por um processo de “desmundanização” (Entweltlichung) no qual elas são isoladas de seu contexto prático, possibilitando a visão teórica do mundo (GA 2, p. 150). É com base nessa visão derivada e reduzida de mundo que se dá o projeto geométrico do espaço. Ao contrário do espaço teórico, no qual as distâncias entre as coisas são quantitativamente mensuráveis, no espaço originário da lida cotidiana as coisas possuem lugares próprios em função do seu uso: "todo aonde (alle Wo) é descoberto pelas direções e caminhos da lida cotidiana e interpretado pela circunvisão, e não estabelecido e enumerado na medição espacial que considera” (GA 2, 138). É a partir da nossa lida com as coisas que se estabelecem as direções (Richtungen) e cercanias (Gegende) e não devido a uma distância matematicamente mensurável. À semelhança do mundo mítico descrito por Cassirer cinco anos antes do surgimento de Ser e Tempo, a distância entre as coisas se dá devido a relações de afinidade em um determinado contexto significativo, o perto e longe são pensados a partir daquilo que está à mão: “o Dasein tem uma tendência geral à proximidade” (GA 2, p.141). Assim, segundo o conhecido jogo de palavras de Heidegger, a espacialidade do Dasein é marcada por um distanciamento Ent-fernung que é, ao mesmo tempo, aproximação (Näherung): “Dasein é essencialmente dis-tanciador (ent-fernend), por ser o ente que é, deixa cada ente dar-se na proximidade” (GA 2, p.140).

Apesar de algumas semelhanças entre as descrições do espaço mítico e da espacialidade do Dasein, evidentemente não se trata aqui do mesmo espaço. Heidegger faz questão de deixar isso claro em seus comentários sobre o Dasein primitivo, no parágrafo 11 de Ser e Tempo: “cotidianidade não coincide com primitividade", sendo a primeira mais fundamental por tratarse de uma estrutura existencial do Dasein em geral, independente de ele viver em uma sociedade altamente desenvolvida ou em uma cultura tradicional. O Dasein primitivo também "tem sua cotidianidade específica”, que não se confunde com a construção cultural do mito. Entretanto, 
Heidegger reconhece que o estudo dos “povos primitivos” poderia ter uma função metodológica positiva para analítica existencial "na medida em que os fenômenos primitivos são menos complicados e estão menos encobertos por uma autointerpretação já desenvolvida do Dasein em questão". Nesse sentido o Dasein primitivo fala mais diretamente "a partir de um emergir mais originário nos fenômenos”. (G A 2, p. 68). Mas, para tanto, as investigações sobre o Dasein primitivo deveriam ser feitas a partir de uma ciência fundamentada na analítica existencial, e não simplesmente no método das ciências positivas. Em uma nota a essas considerações, Heidegger se refere diretamente a Cassirer, destacando a importância de seu trabalho sobre o Dasein mítico, mas questionando os pressupostos neokantianos de suas análises e afirmando a necessidade de fundar as investigações cassirerianas em uma analítica existencial. (GA 2, p. 69, nota 1$)$.

Cassirer, por sua vez, comenta as reflexões de Heidegger sobre a espacialidade e a temporalidade do Dasein no terceiro volume da sua Filosofia das Formas Simbólicas. Como era de se esperar, a partir de seu ponto de vista interpretativo, Cassirer elogia a interpretação de Heidegger sobre o espaço, mas vê nela apenas uma descrição da espacialidade pragmática, a qual seria apenas um estágio a ser descrito dentro do conjunto das formas simbólicas:

\begin{abstract}
Nossa consideração e tarefa própria se diferem da de Heidegger sobretudo pelo fato de que ela não permanece nesse nível do à-mão (Zuhandenes) e seu modo de espacialidade, mas que, sem questionála de forma alguma, pergunta para além dela. Ela [a nossa] quer seguir o caminho que conduz da espacialidade como um momento do à-mão ao espaço como forma do simplesmente-dado (Vorhandenes). E ela quer mostrar ainda mais como esse caminho atravessa a região da formulação simbólica: no duplo sentido de representação e significação (Cassirer, 2010c, p. 167-68. nota 64).
\end{abstract}

Cassirer faz a mesma observação em relação à temporalidade originária abordada por Heidegger em Ser e Tempo. Embora não a questione, afirma que seu projeto filosófico começa justamente na parte de Ser e Tempo ainda não escrita (e nunca escrita) por Heidegger, a saber, na passagem da temporalidade existencial para uma forma do tempo que ultrapassa a existência do Dasein: “Assim como no espaço, também com o tempo, aquilo que constitui seu tema

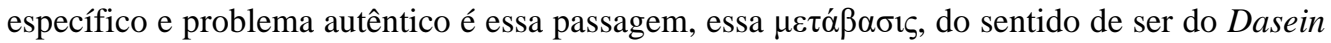
para o sentido 'objetivo' do 'logos'” (Cassirer 2010c, p. 184nota 86).

Nesse ponto do debate fica claro, que "o que para Cassirer pertence apenas ao modo temporário do mito, para Heidegger pertence ao modo da compreensão humana enquanto tal.” (Gordon, 2012, p. 253). O que para Cassirer é o ponto mais elevado das formas simbólicas, para Heidegger é um modo derivado e reducionista, responsável pela desmundanização da experiência originária do mundo. A passagem da Zuhandenheit para Vorhandenheit é para Cassirer a condição do surgimento da filosofia, para o Heidegger de Ser e Tempo ela representa a perda da origem sobre a qual a filosofia deve se edificar.

Mais ainda, para Cassirer a filosofia surge e alcança sua maturidade justamente na ruptura com o mito:

Pois o conceito de filosofia conquista sua força e pureza completas apenas ali, onde ela abandona a constituição de mundo que se expressa nos conceitos linguísticos e míticos, quando ela é em princípio superado. A "lógica da filosofia” se constitui nessa superação.

Essa citação mostra que as divergências entre Heidegger e Cassirer se acentuam ainda mais quando pensadas a partir da interpretação mito-poética que Heidegger fará da história do ser na década de 1930, na qual a filosofia é vista como uma resposta a um início mítico poético do pensamento grego. 


\title{
4. O conflito das origens
}

Pelo que foi exposto, o problema da origem torna-se central para a compreensão da discórdia entre Heidegger e Cassirer. Isso fica claro nas objeções que Heidegger faz de forma mais detida em uma revisão de 1928 sobre o volume dois da Filosofa das Formas Simbólicas. Ali se torna claro que o problema da origem constitui o ponto que separa os dois filósofos. Assim, Heidegger afirma que, ao fazer do mito uma forma funcional de autodeterminação do espírito, Cassirer já pressuporia um modo de ser do Dasein como estando vinculado a noção kantiana de sujeito como pura espontaneidade enquanto lugar transcendental no qual se dá a constituição do mundo mítico. Heidegger afirma, como fará depois em Davos, que falta a Cassirer uma análise ontológica da constituição de ser daquilo que ele, de modo impreciso, denomina de espírito e que seria visto como a origem das formas simbólicas:

\begin{abstract}
trata-se antes de tudo de esclarecer os pressupostos fundamentais do problema que a abordagem do mito como uma forma funcional do "espírito" esconde em si. Apenas a partir disso pode também ser decidido se, e em que medida, uma transposição do questionamento, do esquema, kantiano é intrinsecamente possível e justificável. A interpretação essencial do mito como uma possibilidade do Dasein humano permanece aleatória e sem direção enquanto não puder ser fundada em uma radical ontologia do Dasein à luz do problema do ser (GA 3, p. 265).
\end{abstract}

Essa mesma objeção é retomada em Davos, quando da discussão sobre o lugar da metafísica na crítica kantiana. Assim, Heidegger identifica a doutrina do esquematismo, na Crítica da Razão Pura, como cerne da metafísica kantiana, o que permite remeter a questão fundamental da metafísica, a pergunta pelo ente enquanto tal, ao tempo e à finitude humana, mostrando que Kant já teria apontado, sem que soubesse, para a necessidade de uma analítica existencial. Para Cassirer, “O tema 'Kant e o problema da metafísica' não pode ser tratado exclusivamente sub specie do capítulo do esquematismo, e sim sub specie da doutrina kantiana das ideias e, em especial, sub specie da doutrina kantiana da liberdade e de sua doutrina do belo". (Cassirer, 1931, p.18). Assim, segundo Cassirer, Heidegger baseara sua análise da metafísica kantiana no terminus a quo, na temporalidade finita como origem dos diversos sentidos de ser, enquanto a verdadeira metafísica de Kant encontrar-se-ia no terminus ad quem, nos fins últimos da razão, expressos sobretudo na Crítica da Razão Prática onde a essência humana é pensada a partir da ideia de liberdade. Seria, portanto, no campo das ideias da razão, as quais não encontram nenhum correspondente nos esquemas da imaginação, que a essência do homem deveria ser buscada.

Com razão Heidegger observa que a Filosofia das Formas Simbólicas de Cassirer identifica o terminus ad quem com as diversas formas simbólicas da cultura. Entretanto, o terminus a quo, a origem dessas configurações simbólicas, permanece problemático, sendo atribuído, de modo demasiado vago, ora às forças criativas do espírito, ora à consciência, ora à vida, à razão, etc. Sem uma elaboração precisa da constituição de ser desses domínios, que só poderia ser feita pela analítica existencial, uma filosofa da cultura que busca elaborar um sistema das formas simbólicas careceria de fundamento.

E aqui Cassirer aponta aquilo que seria o ponto de ruptura entre seu pensamento e o de Heidegger. Esse último não teria compreendido a interpretação que Cassirer faz da revolução copernicana de Kant quando, ao questionar os pressupostos transcendentais da Filosofia das Formas Simbólicas, afirmara que Cassirer ainda estaria preso a uma filosofia que vê a subjetividade humana como lugar da constituição do mundo objetivo: "Parece-me que o novo nessa revolução está no fato de que agora já não há uma única estrutura de ser, mas sim que possuímos estruturas de ser totalmente distintas. Cada nova estrutura de ser possui seus novos pressupostos a priori.” (GA 3, p. 294) Assim, por exemplo, a arte constrói um mundo cujas leis são distintas do mundo da física. Deste modo, segundo Cassirer: 
O ser da antiga metafísica era a substância, aquilo que subjaz. O ser da nova metafísica, na minha linguagem, já não é o ser de uma substância, mas sim o ser que surge de uma multiplicidade de determinações e significações funcionais. E aqui me parece estar o ponto fundamento da diferença entre a minha posição e a de Heidegger (GA 3, p. 294).

Desse ponto de vista, até mesmo a ontologia fundamental de Heidegger parece recair em uma metafísica da origem. Apesar de Heidegger, por um lado, insistir no fato de que o ser-aí não pode ser interpretado a partir da noção de Vorhandenheit e, portanto, não pode ser pensado como algo substancial, por outro lado ele atribui ao ser-aí uma estrutura temporal prévia que antecede toda doação de sentido, uma temporalidade originaria da qual derivam os tempos da ciência, do mito, etc., tomada como horizonte transcendental para a compreensão do ser. Ora, como vimos, para Cassirer o que ocorre é justamente o contrário, assim como o espaço, o tempo adquire sua estrutura a partir da unidade simbólica de sentido na qual ele se insere. Cada vez que o tempo é pensado segundo uma ordenação mítica, estética ou teórica, muda-se também a “forma” e a estrutura do tempo. Podemos dizer que em Cassirer a função de sentido é sempre anterior a estrutura do tempo, ao passo que em Heidegger o tempo possui uma estrutura prévia que é origem desde a qual o sentido emerge. Do ponto de vista de Cassirer, postular uma temporalidade originária como horizonte transcendental para compreensão do sentido do ser, como faz Heidegger, seria hipostasiar uma determinada função ordenadora do tempo, tomandoa como origem do sentido: seria querer dotar o tempo de uma estrutura originária, anterior às configurações de sentido.

Em Davos, interpretação que Cassirer faz do local da "metafísica” na crítica kantiana nos revela, ao mesmo tempo, qual seria a origem que daria unidade ao seu sistema das formas simbólicas. A referência à doutrina das ideias indica que "o fim comum” para qual todas as formas simbólicas trabalham está intimamente relacionado à ideia de liberdade, o que confere à filosofia das formas simbólicas um conteúdo ao mesmo tempo epistemológico e moral.

Com efeito, em Um Ensaio Sobre o Homem, no capítulo intitulado "Fatos e Ideais”, Cassirer afirma que, para Kant, o que distingue o conhecimento humano das demais formas de conhecimento é a capacidade de separar o real do possível. Os animais não possuem essa capacidade, pois vivem presos aos estímulos sensíveis. Deus não necessita fazer essa distinção, já que seu conhecimento não é discursivo, mas ato puro dado em uma pura intuição. O intelecto divino é um intuitus originarius que, ao mesmo tempo que intui, cria o objeto intuído. Seria na distinção entre o real e o possível que se encontraria a limitação e ao mesmo tempo o poder criativo do ser humano em todas as suas manifestações culturais. Assim, por exemplo, sem a hipótese de um corpo sem qualidades sensíveis determinadas, que se move em um espaço retilíneo e sem a ação de qualquer força externa (um corpo empiricamente impossível), Galileu jamais teria chegado à lei da inércia. Da mesma forma, os grandes sistemas religiosos, éticos e políticos trabalham com uma ideia utópica de um mundo melhor, de uma humanidade ou de um estado ideais:

tomada como um todo, a cultura humana pode ser descrita como um processo da progressiva autolibertação do homem. A linguagem, a arte, a religião e a ciência são as várias faces desse processo. Em todas elas o homem descobre e experimenta um novo poder - o poder de construir um mundo só dele, um mundo ideal (Cassirer, 1992, p.228).

Assim, se é possível pensar em um "núcleo unificador" que confere unidade ao sistema das formas simbólicas, ele não pode ser pensado a partir de uma unidade de origem, mas antes como uma tarefa ideal de autolibertação do ser humano, cujo único fim seria "transformar o mundo passivo das meras impressões, nas quais o espírito primeiramente se encontra aprisionado, em um mundo de pura expressão espiritual”. (Cassirer, 2010, p.10)

E aqui, mais uma vez, os dois filósofos tomam caminhos diametralmente opostos. É precisamente no caráter meramente funcional do símbolo, nessa precedência das relações 
matemáticas sobre as coisas, que Cassirer vê o maior grau de idealização e de realização do projeto filosófico de autolibertação do homem. Heidegger, ao contrário, vê nisso um dos modos mais ameaçadores da técnica, na qual o ser é esquecido em nome do mera calculabilidade.

Com efeito, na palestra Ciência e Pensamento Meditativo (Wissenschaft und Besinnung), Heidegger afirma que o formalismo matemático da física atômica leva ao extremo a relação sujeito e objeto, na mediada em que nele "a relação-sujeito-objeto adentra assim em sua pura "relação", ou seja, em seu caráter de demanda, no qual tanto o sujeito como o objeto são tomados como meros componentes para a manipulação técnica de tudo que existe”(GA 7, p. 55). Onde Cassirer identifica o maior grau de liberdade humana, Heidegger vê o aprisionamento do humano pela essência da técnica.

É em função de seu projeto libertário e iluminista da filosofia que Cassirer, em O Mito do Estado, seu último escrito publicado postumamente, analisará a ascensão do nacionalsocialismo e direcionará críticas diretamente a Heidegger. Nessa obra, o nazismo é explicado pela irrupção do elemento mítico em uma sociedade cujos pilares deveriam se assentar em um pensamento iluminista. O momento de extrema penúria e desespero no qual a Alemanha se encontrava após a primeira guerra teria enfraquecido todos meios racionais e institucionais empregados pela república de Weimar. Assim como nas sociedades "primitivas" onde, em momentos de desespero, apela-se para a mágica e para busca de um "Grande Homem" que possa salvar a sociedade da penúria, assim também a Alemanha teria apelado para uma relação mágica e emotiva com o estado, baseada em uma ligação orgânica entre os membros de uma comunidade, pelo culto ao herói e ao estado personificado na figura do Führer como salvador da pátria. Porém, como um retorno do mito em estado puro é algo impossível na nossa sociedade tecnológica, o mito do estado moderno surge travestido de racionalidade, nele há uma mistura entre mágica e técnica, uma fusão entre duas funções simbólicas:

O político moderno teve de combinar em si mesmo duas funções inteiramente diferentes e incompatíveis. Ele deve agir ao mesmo tempo como um homo magus e um homo faber. Ele é o sacerdote de uma religião nova, irracional e misteriosa. Mas quando ele deve defender e propagar essa religião, ele procede muito metodicamente. Nada é deixado ao acaso, cada passo é bem preparado e premeditado. Essa estranha combinação é um dos traços mais surpreendentes do nosso mito político (Cassirer, 1955, p. 354).

No campo intelectual, Cassirer aponta Heidegger e "a nova filosofia existencial” como um dos fatores que ajudaram a enfraquecer a crença na razão e na ciência e facilitar a ascensão dessa visão mítica da política no seio da modernidade. Isso não significa que Heidegger tivesse essa intenção, ao contrário, Cassirer admite que as investigações heideggerianas têm um "suporte bastante 'realista' e não 'especulativo'. Mas a nova filosofia enfraquece e mina lentamente as forças que poderiam resistir aos modernos mitos políticos” (Cassirer, 1955, p. 369). Cassirer interpreta a Geworfenheit - o fato de o Dasein ser sempre um projeto lançado temporalmente no mundo como horizonte de sentido - como sendo a defesa de um certo fatalismo por parte de Heidegger no qual podemos interpretar nossas condições históricas de existência, mas não modificá-las.

Desse modo, no $O$ Mito do Estado Heidegger aparece incorporado a um movimento que começara com Spengler, autor que previa o declínio cultural inevitável do ocidente e afirmava sua última possibilidade de sobrevivência na técnica e na política. É curioso observar que Cassirer reprova Spengler quando este afirma que a natureza deveria ser tratada cientificamente e história poeticamente. Aqui o escritor estaria misturando poesia e filosofia da história, quando o verdadeiro poeta sabe distinguir o mundo de sua imaginação daquele dos fatos (Cassirer, 1955, p. 364). Em Spengler a função poética e a filosófica parecem se misturarem de modo impróprio. Essa seria também uma crítica que talvez coubesse ao projeto mito-poético de Heidegger dos 
anos 1930, embora isso estivesse fora do escopo de Cassirer. De qualquer modo, Heidegger e Spengler são postos como dois lados da mesma moeda:

\begin{abstract}
Uma filosofia da história que consiste em vaticínios sombrios sobre o declínio e a inevitável destruição da nossa civilização e uma teoria que vê na Geworfenheit do homem uma de suas principais características, ambas têm abandonado todas as esperanças em ativamente tomar parte na reconstrução da vida cultural do homem. Tal filosofia renuncia aos seus próprios ideais teóricos e éticos fundamentais. Assim ela pode ser usada como um instrumento flexível nas mãos de líderes políticos (Cassirer 1955, p. 369).
\end{abstract}

Embora essa crítica nos pareça injusta quando aplicada à analítica existencial, ela não é totalmente descabida quando estendida à interpretação mito-poética da história do ser. É curioso que as análises de Cassirer sobre o mito pareçam se adequar mais ao projeto político que Heidegger desenvolve no início dos anos de 1930, do que à analítica existencial que se torna o alvo de suas críticas, sobretudo quando atentamos para o modo como Cassirer descreve o tempo mítico. "O verdadeiro caráter do ser-mítico se revela apenas ali, onde ele surge como ser da origem (Ursprung)” Cassirer, 2010b p. 131. É nessa origem que os deuses, os seres humanos e a própria natureza encontram seu início e sua justificativa. Entretanto, assim como o espaço, o tempo mítico não flui em uma única direção: presente, passado e futuro estão reunidos em um único momento. O “agora mágico” não é um mero ponto no presente, mas “contém em si o passado e está prenhe de futuro” (Cassirer, 2010b p. 131).

Essa temporalidade mítica se assemelha àquela da interpretação mito-poética da história do ser. Heidegger parecia então acreditar em um evento originário que inaugura a história e determina o destino de um povo, cuja força está sempre latente e pode ser “evocada” de alguma forma.

\title{
5. Considerações finais
}

A nosso ver, o afastamento, a divisão de caminhos, entre Heidegger e Cassirer se deve, em grande parte, à interpretação que cada um dos filósofos faz acerca da origem das diversas aberturas de sentido, ou seja, dos diferentes modos de ser pelos quais compreendemos as coisas. Daí surgem ontologias distintas que irão implicar concepções diametralmente opostas sobre a origem da filosofia e da política.

Como vimos, Heidegger pensa o ser a partir de uma origem única, identificada primeiramente com a temporalidade originária do Dasein e, posteriormente no início dos anos de 1930, com os envios epocais do próprio ser, cuja força está no início mito-poético do povo grego. É a força desse primeiro início que possibilita a filosofia como história do ser. Assim, uma transformação política também deveria se dar de forma súbita, em um instante revolucionário, a partir da evocação da força desse primeiro início.

Cassirer, por sua vez, pensa a origem a partir das várias formas simbólicas da cultura humana, a qual é tomada como um projeto de autolibertação do homem que se realiza no confronto e no entendimento entre as diversas funções simbólicas. Isso se traduzirá em uma concepção essencialmente contratualista da política, a qual não pode se fundar em nenhuma força sobre-humana, mas unicamente na espontaneidade criativa do espírito humano guiada pela razão iluminista.

Estaria Heidegger padecendo de um mito da origem, ou seria Cassirer quem sofre de uma crença ingênua no poder de autodeterminação do ser humano? Haveria um meio termo possível entre essas duas ontologias? 


\section{Referências}

CASSIRER, Ernst (1922) Die Begriffsform im mythischen Denken. Leipzig - Berlin, B.G. Teubner.

CASSIRER, Ernst (1931) “Kant und das Problem der Metaphysik. Bermerkungen zu Martin Heideggers Kant Interpretation“, Kant-Studien, 36.

CASSIRER, Ernst (1955) The Myth of the State. Doubleday Anchor, Garden City, N.Y.

CASSIRER, Ernst (1992) An Essay on Man. Yale University Press, New Haven and London.

CASSIRER, Ernst (2009a.) Linguagem e Mito. Perspectiva, São Paulo

CASSIRER, Ernst (2009b) Schriften zur Philosophie der symbolischen Formen, Meiner, Hamburg (ebook).

CASSIRER, Ernst (2010a) Philosophie der symbolischen Formen: Erster Teil - Die Sprache. Meiner, $\mathrm{H}$ amburg

CASSIRER, Ernst (2010b) Philosophie der symbolischen Formen: Zweiter Teil - Das mythische Denken. Meiner, Hamburg

CASSIRER, Ernst (2010c) Philosophie der symbolischen Formen: Dritter Teil Phänomenologie der Erkenntnis. Meiner, Hamburg

CASSIRER, Ernst (2012) Ensaio sobre o Homem. Martins Fontes, São Paulo.

FRIEDMAN, Michael (2011) A Parting of the Ways. Open Court, Chicago.

GORDON, Peter E. (2012) Continental Divide. Harvard U. Press. Cambridge.

HEIDEGGER, Martin, GA 2, Sein und Zeit. ed. FW. Von Herrmann, Frankfurt a.M., V. Klostermann, 1977.

HEIDEGGER, Martin, GA 3, Kant und das Problem der Metaphysik. ed. FW. Von Herrmann, Frankfurt a. M. Vittorio Klostermann, 1990.

HEIDEGGER, Martin, GA 7. Vorträge und Aufsätze. ed. Hermann Heidegger, Frankfurt a.M. V., Klostermann, 2000.

HEIDEGGER, Martin, GA 16, Reden und andere Zeugnisse eines Lebensweges. ed. Hermann Heidegger, Frankfurt a.M. V., Klostermann, 2000

HEIDEGGER, Martin (1997) "Discurso da Reitoria”, tradução de Fausto Castilho. Curitiba: Secretaria de Estado da Cultura. (edição bilingue: Alemão-Português).

HEIDEGGER, Martin, GA 39. Hölderlins Hymnen „Germanien“ und „der Rhein“. ed. Susanne Siegler, Frankfurt a.M., V. Klostermann, 1999.

HEIDEGGER, Martin, GA 40, Einführung in die Metaphysik. ed. Petra Jaeger, Frankfurt a.M., V. Klostermann, 1983.

HEIDEGGER, Martin, GA 94, Überlegungen II - VI (Schwarze Hefte 1931 -1938). ed. Peter Trawny. Frankfurt a.M., V. Klostermann, 2014

HEIDEGGER, Martin, GA 95, Überlegungen VII - XI (Schwarze Hefte 1938/1939). ed. Peter Trawny. Frankfurt a.M., V. Klostermann, 2014

HEIDEGGER, Martin, GA 96, Überlegungen XII - XV (Schwarze Hefte 1939 -1941). ed. Peter Trawny. Frankfurt a.M., V. Klostermann, 2014

HEIDEGGER, Martin, GA 97, Anmerkungen I-V (Schwarze Hefte 1942-1948). ed. Peter Trawny. Frankfurt a.M., V. Klostermann, 2015

HEIDEGGER, Martin, GA 98, Anmerkungen VI-IX (Schwarze Hefte 1948/49-1951), ed. Peter. Trawny, Frankfurt a.M., V. Klostermann 2018

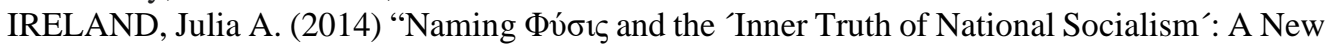
Archival Discovery”. Research in Phenomenology n. 44 pp. 315-346

MEYER, Daniel (2009) „Die Entdeckung des griechischen Mythos: Heideggersgeschichtsphilosophische Wende“, Germanica. Doi: https://doi.org/10.4000/germanica.805 
SAFRANSKI, Rüdiger (1998) Ein Meister aus Deutschland - Heidegger und seine Zeit. Frankfurt a.M.: Fischer Verlag.

TRAWNY, Peter (2014) Heidegger und der Mythos der jüdischen Weltverschwörung. Frankfurt a.M., V. Klostermann.

VIETTA, Silvio (1993) Heidegger Critique du National-socialisme et de la Technique. Puiseaux: Pardès.

ZABOROWSKI, Holger (2010) “Eine Frage von Irre und Schuld?": Martin Heidegger und der Nationalsozialismus. Fischer (e-book).

ZIMMERMAN, Michael E. (1990) Heidegger's confrontation with modernity: technology, politics, and art. Bloomington: Indiana University Press. 